\title{
A NOTE ON COMMUTATIVITY PRESERVING MAPS ON $M_{n}(\mathbb{R})$
}

\author{
Gregor Dolinar, Bojan KuZMa And JANKo Marovt
}

Abstract. Let $M_{n}(\mathbb{F})$ be the set of all $n \times n$ matrices over a field $\mathbb{F}$. Surjective maps which preserve the commutativity relation on $M_{n}(\mathbb{F})$ only in one direction have been recently classified for the case when $\mathbb{F}$ is an algebraically closed field. We show that the same result holds also when $\mathbb{F}=\mathbb{R}$ is the field of real numbers and $n \geqslant 7$ is odd.

Mathematics subject classification (2010): 15A27, 47B49, 15A04.

Keywords and phrases: Non-linear preserver, commutativity, centralizer, commuting graph.

\section{REFERENCES}

[1] J. Aczél, J. Dhombres, Functional equations in several variables, Encyclopedia Math. Appl. 31, Cambridge University Press, Cambridge, 1989.

[2] J. BRAČIČ AND B. KUZMA, Reflexivity defect of spaces of linear operators, Linear Algebra Appl. 430 (2009), no. 1, 344-359.

[3] M. D. ChOI, A. A. JAFARIAN, AND H. RADJAVI, Linear maps preserving commutativity, Linear Algebra Appl. 87 (1987), 227-241.

[4] G. Dolinar And B. KuZMa, Homomorphisms of commutativity relation, Linear Multilinear Algebra 64 (2016), no. 5, 897-922.

[5] G. Dolinar, A. E. Guterman, B. Kuzma, and P. Oblak, Extremal maximal centralizers, Linear Algebra Appl. 438 (2013), no. 7, 2904-2910.

[6] C.-A. FAURE, An elementary proof of the fundamental theorem of projective geometry, Geom. Dedicata 90 (2002), no. 1, 145-151.

[7] A. Fošner, Commutativity preserving-maps on $M_{n}(\mathbb{R})$, Glas. Mat. 44 (2009), no. 1, 127-140.

[8] J. M. Grau, A. Oller-MarcÉn, And C. TASis, On the diameter of the commuting graph of the full matrix ring over the real numbers, Bull. Iranian Math. Soc. 43 (2017), no. 1, 217-221.

[9] R. A. Horn And C. R. Johnson, Matrix Analysis, Cambridge University Press, Cambridge, 1985.

[10] N. JACOBSON, Lectures in algebra, volume II: linear algebra. Vol. 31, Graduate texts in mathematics, Springer-Verlag, New York, 1953.

[11] C. Miguel, A note on a conjecture about commuting graphs, Linear Algebra Appl. 438 (2013), no. $12,4750-4756$.

[12] P. ŠEMRL, Non-linear commutativity preserving maps, Acta. Sci. Math. (Szeged) 71 (2005), 781-819.

[13] P. ŠEMRL, Commutativity preserving maps, Linear Algebra Appl. 429 (2008), 1051-1070. 